\title{
DICUMBA: UMA PROPOSTA METODOLÓGICA DE ENSINO A PARTIR DA PESQUISA EM SALA DE AULA
}

\author{
EVERTON BEDIN ${ }^{*}$ \\ https://orcid.org/0000-0002-5636-0908 \\ JOSÉ CLAUDIO DEL PINO" "** \\ https://orcid.org/0000-0002-8321-9774
}

RESUMO: Compreendendo que, às vezes, a metodologia docente utilizada em sala de aula faz com que o processo de ensino-aprendizagem se desenvolva de forma não qualificada, arbitrária e linear, este artigo propõe a metodologia Dicumba; uma metodologia de pesquisa em que o estudante se torna construtor dos próprios saberes a partir da vivência, da curiosidade e do interesse. A metodologia foi desenvolvida em uma perspectiva de conhecimento modelado a partir da teia construtivistacolaborativa, possibilitando um planejamento de educação real e sistematizado, fundamentado na aprendizagem e no pleno desenvolvimento do sujeito. Esta constitui a figura do professor como um facilitador do processo de aprendizagem, instigando o aluno, por meio da emoção e da problematização, a se compor como responsável pela sua formação, construindo e reconstruindo conhecimentos através das descobertas.

Palavras-chave: Professor facilitador; Aluno protagonista; Metodologia Dicumba.

\section{DICUMBA: UNA PROPUESTA METODOLÓGICA DE ENSEÑANZA A PARTIR DE LA INVESTIGACIÓN EN CLASE}

RESUMEN: Por comprender que, a veces, la metodología docente utilizada en clase hace que el proceso de enseñanza-aprendizaje se desarrolle de forma no cualificada, arbitraria y lineal, este artículo propone la metodología Dicumba; una metodología de investigación en que el estudiante se vuelve constructor de los propios saberes a partir de la vivencia, de la curiosidad y del

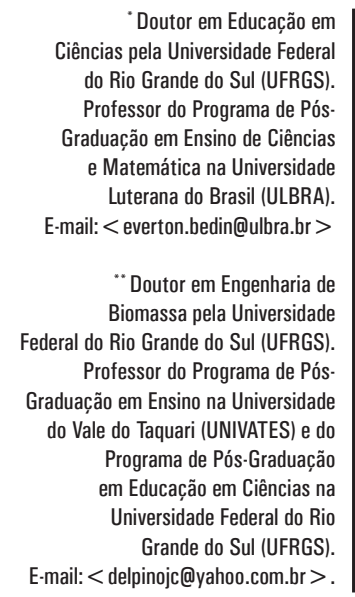

\footnotetext{
' Universidade Luterana do Brasil, Programa de Pós-Graduação em Ensino de Ciências e Matemática, Canoas, RS - Brasil.

" Universidade Federal do Rio Grande do Sul, Programa de Pós-Graduação em Educação em Ciências, Porto Alegre, RS - Brasil.
} 
interés. La metodología se desarrolló desde una perspectiva de conocimiento modelado a partir de la red constructivistacolaborativa, lo que posibilitó un planeamiento de educación real y sistematizado, fundamentado en el aprendizaje y en el desarrollo pleno del sujeto. Esta constituye la figura del profesor como un facilitador del proceso de aprendizaje, lo que incita el alumno, por medio de la emoción y de la problematización, a responsabilizarse de su formación, construyendo y reconstruyendo conocimientos a través de los descubrimientos.

Palabras clave: Profesor facilitador; Alumno protagonista; Metodología Dicumba.

\section{DICUMBA: A METHODOLOGICAL PROPOSAL OF TEACHING FROM THE CLASSROOM RESEARCH}

ABSTRACT: Understanding that, sometimes, a teaching methodology used in the classroom causes the processes of teaching-learning to develop in an unqualified, arbitrary and linear way, this article proposes the Dicumba methodology; a research methodology in which the student becomes a constructor of his own knowledge using the experience, curiosity and interest. The methodology was developed from a perspective of knowledge shaped from a constructivistcollaborative web, allowing real and systematized education planning, based on the learning and full development of the subject. The methodological proposal is a teacher figure as a facilitator of the learning process, prompting the student, through the emotion and questioning, to be composed as responsible for their training, constructing and reconstructing knowledge through discoveries.

Keywords: Professor facilitator; Student protagonist; Dicumba Methodology. 


\section{INTRODUÇÃO}

A metodologia que o professor da Educação Básica utiliza nos ambientes de aprendizagem nas diferentes escolas, a fim de despertar no estudante a curiosidade pelo conhecimento e a busca por novas informações, é, basicamente, resultado de sua formação inicial. Esta formação inicial é adquirida na Universidade durante o desenvolvimento do curso de Licenciatura, seja por meio de atividades teóricas, práticas, de forma extraclasse ou, até mesmo, a exemplo da figura do professor. Indiferente da forma de agregação de metodologias durante a formação inicial do professor, estas precisam proporcionar-lhe conhecimentos e aportes o suficiente para que este possa trabalhar com um grupo heterogêneo de sujeitos na educação básica.

Neste sentido, alguns documentos básicos, os quais regem a formação docente, como as Diretrizes Curriculares Nacionais para formação de professores da Educação Básica (BRASIL, 2012), demonstram a importância de a metodologia utilizada permitir o desenvolvimento de reflexão continuamente. Basicamente, neste documento é possível fazer uma leitura que fundamenta e referencia a ideia de que, nos cursos de formação docente oferecidos nas universidades, há a necessidade de apresentar um conjunto de competências necessárias à atuação profissional, fazendo-as norteadoras e fundamentais do desenvolvimento da ação docente à luz da proposta pedagógica, do currículo, da organização institucional e, principalmente, da gestão da escola de formação.

Em especial, no artigo $1^{\circ}$ das Diretrizes Curriculares Nacionais para a Formação de Professores da Educação Básica em nível superior (Licenciatura Plena), encontram-se as ideias de que estas se constituem como um "conjunto de princípios, fundamentos e procedimentos a serem observados na organização institucional e curricular de cada estabelecimento de ensino e aplicam-se a todas as etapas e modalidades da educação básica" (BRASIL, 2002, p. 1). Em comunhão, no artigo $2^{\circ}$ do mesmo documento, é possível observar as indicações de que a organização curricular de cada instituição precisa, além do disposto na Lei 9.394, de dezembro de 1996, desenvolver outras formas de orientação intrínsecas à formação docente para uma ação de qualidade, entre as quais o preparo para:

I - o ensino visando à aprendizagem do aluno; II - o a colhimento e o trato da diversidade; III - o exercício de atividades de enriquecimento cultural; IV - o aprimoramento em práticas investigativas; V - a elaboração e a execução de projetos de desenvolvimento dos conteúdos curriculares; VI - o uso de tecnologias da informação e da comunicação e de metodologias, estratégias e materiais de apoio inovadores; e VII - o desenvolvimento de hábitos de colaboração e de trabalho em equipe. (p. 1).

Neste sentido, e seguindo as ideias norteadoras das DCN para a formação de professores, percebe-se que o professor, ao sair da universidade, precisa estar comprometido com o ensino básico de forma qualificada, apresentando habilidades para se expressar de forma clara e objetiva, avaliar o sistema educacional, os livros didáticos e as propostas de avaliação da escola, além de desenvolver metodologias diferenciadas para facilitar os processos de ensino e aprendizagem e colocar o estudante como centro de sua formação, utilizando as tecnologias, os trabalhos em grupo ou por planejamento em equipe multidisciplinar. 
Na perspectiva debuscar alternativas para uma proposta de desenvolvimento dessas competências na formação inicial de professores, apresenta-se neste trabalho uma proposta de metodologia que pode assegurar, quando desenvolvida de forma eficiente, a aquisição de saberes expressivos na aprendizagem do aluno. Em outras palavras, no presente artigo objetiva-se apresentar uma metodologia intitulada Dicumba; desenvolvida pelo pesquisador durante discussões relevantes sobre a ideia do estudante tornar-se, com o auxílio do professor, construtor dos próprios saberes; saberes estes que, ressignificados cientificamente ao seu contexto sociocultural, emergem a partir de sua vivência, curiosidade e interesse; logo, o aluno tem a capacidade de intervir de forma satisfatória no meio em que vive. Portanto, trata-se de uma metodologia que teve como motivação e princípio de emersão as angústias, as incertezas e os sentimentos envolvidos na construção de projetos de pesquisa lato (Especialização) e stricto sensu (Mestrado e Doutorado) realizados à luz do Ensino de Química na Educação Básica.

Assim, tem-se que este trabalho se torna relevante na medida em que se entende que a formação dos saberes do aluno deve partir de sua vivência e de seu interesse para que possam fazer/trazer sentido e significado. Além disto, o professor, ao desenvolver o ensino por meio da metodologia Dicumba, potencializará a aprendizagem do aluno através da pesquisa centrada em seu contexto, possibilitando a este a revisão de saberes para a (re)construção de seus conhecimentos.

Neste sentido, ajuíza-se que a metodologia Dicumba foi desenvolvida em uma perspectiva de conhecimento modelado a partir de uma teia construtivistacolaborativa, a qual permite, durante o processo de construção de saberes, a comunicação entre os alunos e entre estes e o professor. Logo, é importante que a metodologia Dicumba esteja presente nas diferentes escolas do país, pois para Rogers (1978) uma relação inovadora, sem opressão e força, capaz de envolver de forma autêntica e aceitadora o papel do aluno no processo da construção de sua aprendizagem faz com que o mesmo, lentamente, desenvolva uma nova consciência de si, desvinculando-se dos valores que lhe foram atribuídos por outrem, atribuindo sentido às próprias vivências. Em outras palavras, por meio da metodologia Dicumba o aluno passa a conhecer-se e transcender-se ao vivido imediato para tornar-se pessoa completa ao assumir-se e dar significado àquilo que é importante para sua própria vida.

\section{TRABALHOS CORRELATOS E A INÓPIA DA METODOLOGIA DICUMBA}

Com base em alguns trabalhos investigados e interpretados acerca do objetivo desta pesquisa, e em autores que discutem a formação e a prática docente e o desenvolvimento do ensino com vistas à inserção da pesquisa em sala de aula, pode-se perceber que é recorrente e constante o desafio de ensinar e aprender por meio da pesquisa em sala de aula. Contudo, nenhum trabalho à luz do objetivo deste artigo foi encontrado, uma vez que a metodologia que aqui se apresenta, por mais que tenha traços e aportes epistemológicos semelhantes à concepção de alguns autores, apresenta-se em um viés diferenciado.

Um dos artigos analisados, além de trazer a ideia de que a prática docente deve partir da pesquisa para ser qualificada formal e politicamente, traz a pesquisa 
como meio de aperfeiçoamento na formação inicial de professores (GALIAZZI; MORAES, 2002). Além disto, os autores, quando remetem a pesquisa à Educação Básica, afirmam que é desafio do professor transformar a visão de que o aluno aprende e o professor ensina, "convertendo os conteúdos a serem trabalhados em pesquisa” (p. 238); logo, percebe-se que a pesquisa deriva do conteúdo científico e não do interesse do aluno.

O trabalho de Galiazzi, Moraes e Ramos (2003) traz uma discussão do Educar pela Pesquisa na formação docente, centrando-se em categorias de resistência. Estas categorias emergiram a partir de um estudo com 14 professores em formação. No texto, os autores, além de afirmarem que a pesquisa se aplica na investigação do professor sobre a sua própria sala de aula, afirmam a necessidade de os docentes estarem atentos à resistência, pois esta impossibilita a intervenção consciente e crítica no processo de formação. Ainda, os autores afirmam que a pesquisa ocorre através de um ciclo dialético de três movimentos: questionamento, construção de argumentos e comunicação.

Em seu livro, Demo (2002), assim como os autores supracitados, ressalva a ideia da pesquisa como princípio formativo/pedagógico. Para Demo (2002), a pesquisa, enquanto base do processo de ensinagem, propicia o fazer-se e o refazerse pelo questionamento reconstrutivo, devendo ser incorporada como prática diária do professor e do aluno. De acordo com o autor, o professor se torna pesquisador quando usufrui da pesquisa como viés educativo e formativo. Por fim, o autor determina e diferencia o papel do professor enquanto orientador de um trabalho individual, coletivo e conjunto.

Nos achados de Piccoli e Moraes (2006), evidenciou-se uma discussão sobre a necessidade de a escola e o professor abordarem o Educar pela Pesquisa em sala de aula para modificar o cenário educacional. Os autores apresentam pressupostos para que os professores percebam os alunos, também, como mecanismos de qualificar o ensino, afirmando que a possibilidade de recriar a sala de aula emerge a partir do diálogo, da capacidade argumentativa e da autonomia entre os sujeitos.

No texto de Bertoletti et al. (2003) encontra-se a pesquisa em sala de aula como meio de, além de motivar os alunos à aprendizagem, favorecer o desenvolvimento dos processos de ensino e aprendizagem por meio de tecnologias educacionais. Para tal, os autores afirmam que deve haver motivação e incentivo dos alunos à reconstrução de conhecimentos, a qual é considerada um critério básico do Educar pela Pesquisa. Ao término, os autores apresentam uma forma de inserir o Educar pela Pesquisa em sala de aula, enfatizando o ciclo dialético proposto por Galiazzi, Moraes e Ramos.

Com base nos dados apresentados, percebe-se que nenhum dos autores aborda a ideia do Aprender pela Pesquisa Centrada no Aluno (APCA), intensificando a inópia desta metodologia. A metodologia Dicumba parte do pressuposto de que o aluno é quem determina o que quer estudar. $\mathrm{O}$ aluno, motivado pela curiosidade e pelo interesse, escolhe um tema que emerge de seu contexto de vida, e o professor, como mediador e potencializador da aprendizagem, mediante habilidades, competências e saberes intradisciplinares, problematiza o tema do aluno à luz dos saberes científicos. 


\section{O SURGIMENTO DA METODOLOGIA DICUMBA}

A metodologia que se apresenta neste artigo, intitulada como Dicumba, nasceu durante discussões e reflexões em uma Roda de Conversa sobre metodologias docentes para dar qualidade aos processos de ensino e aprendizagem de ciências na Educação Básica e enriquecer/aperfeiçoar a formação inicial de professores de ciências. Estas Rodas de Conversa, as quais ocorrem por meio de um curso de extensão gratuito e sem fim lucrativo, são dirigidas por um professorpesquisador na área e contam com a participação de dez alunos do curso de Química Licenciatura Plena de uma universidade privada da região metropolitana de Porto Alegre, capital do Estado do Rio Grande do Sul.

A metodologia Dicumba é nomeada a partir da concepção de trabalhar com pesquisa no ensino de ciências, fazendo com que o estudante desenvolva um espírito crítico-cientista por meio das atividades coletivas e dialógicas vinculadas à pesquisa de seu interesse, de sua curiosidade e, principalmente, de seu desejo; a pesquisa ocorre por meio do objetivo discente e é aprimorada com os saberes docentes. Ou seja, a palavra Dicumba procede da ideia da constituição do sujeito enquanto cientista, àquele que tem veemência e curiosidade pelas ciências; o aluno que gosta do conteúdo científico na medida em que consegue, dentro de suas especificidades e singularidades, interpretar os fenômenos naturais que ocorrem em seu entorno e mobilizar suas competências para desenvolver novos saberes.

A proposta de Desenvolvimento cognitivo universal-bilateral da aprendizagem (Dicumba), tem valor relevante na Educação Básica e no aperfeiçoamento da prática docente, pois quando o aluno desenvolve uma pesquisa centrada naquilo que ele tem familiaridade e interesse, automaticamente, apresenta saberes sociais que serão considerados e aprimorados na medida em que a realiza; a pesquisa é universal por se tratar de algo do interesse do aluno, pois ele é quem determina aquilo que irá pesquisar para, em seguida, o professor fazer conexões com o conteúdo científico, demonstrando a bilateralidade da pesquisa, a fim de que juntos possam aprender a aprender por meio da ressignificação de saberes relacionados a um tema sóciohistórico e sociocultural do aluno.

Esta concepção desdobra-se nas conversas entre o pesquisador e os sujeitos em formação, as quais apresentam as concepções das teorias de Vygotsky (1991) e Bakhtin (1999), já que os sujeitos interatuam em busca da construção, do aperfeiçoamento e da reconstrução de saberes; as vozes dos sujeitos são somadas e, juntas, constituem ideias que vinculam, em postura reflexiva autônoma, a competência na formação docente, nos processos de ensino e aprendizagem e, em especial, na formação do aluno da rede pública de ensino.

Além disto, tem-se que as Rodas de Conversa potencializam o diálogo entre os sujeitos em um viés de formação cooperativa, pois há valorização das concepções do outro e compreensão sobre as colocações que se referem à história de vida de cada um. Além do mais, os diálogos, as diferenças individuais e as subjetividades, às vezes, são "atravessadas pelos diferentes significados que um tema desperta em cada participante” (WARSCHAUER, 1993, p. 46). 
Portanto, estes espaços fornecidos para o diálogo são relevantes aos sujeitos por contribuírem "para a formação dos professores de forma significativa, uma vez que lhes possibilitam atualizar saberes, completar as práticas didáticas e ressignificar concepções em relação à formação para o ensino de ciências" (BEDIN; DEL PINO, 2017a, p. 166). Também, nestes momentos em que há qualificação na formação docente ocorrem "estudos, discussões, pesquisa e articulação de saberes entre os sujeitos sobre a ação de ensinar e aprender” (BEDIN; DEL PINO, 2017a, p. 167), pois "são oferecidas diversas formas para que os professores possam criar, recriar e socializar suas práticas e saberes, possibilitando a reflexão sobre a própria formação" (BEDIN; DEL PINO, 2017b, p. 86).

Neste sentido, e em meio às práticas estabelecidas entre os sujeitos das Rodas, entende-se a constante necessidade de o professor da rede pública de ensino aperfeiçoar suas metodologias didáticas e práticas pedagógicas, pois os alunos da contemporaneidade não vivem na inércia; o surgimento de novas tecnologias, dentro de uma nova relação espaço-tempo, traz suficientemente informações rápidas e novas que, mesmo superficialmente, fazem com que os alunos almejem atualizações e busquem essas informações.

Em outras palavras, percebe-se que o aluno precisa buscar informações, construir ideias, trocar experiências e mobilizar suas competências para adquirir o saber teórico-prático; logo, o professor, como peça fundamental para facilitar e nortear o caminho correto para a formação de um cidadão crítico e reflexivo, tem o papel de propiciar ao estudante edificar estruturas cognitivas de formação em uma perspectiva mais significativa à luz da aprendizagem, oportunizando o direito ao questionamento e ao pensar sobre a realidade nos espaços em que ela é produzida.

Assim, Nascimento e Silva (2009, s/p) refletem que o atual momento carece de o professor fazer/realizar "o exercício permanente da crítica sobre quais as estratégias de ensino e de aprendizagem podem nortear o desenvolvimento de competências e habilidades postas no cenário dos desafios contemporâneos". Contudo, é necessário afirmar que "não se trata de aplicar modelos preestabelecidos, mas possibilitar formas para que os profissionais experimentem novas metodologias de ensino, que venham ao encontro das necessidades concretas dos alunos, produzindo saberes reais" (VLACH, 2002, p. 18).

Desta forma, surge a metodologia Dicumba que extrapola a ideia dicotomizada entre a relação ensino e aprendizagem, pois na escola, local privilegiado em que o aluno se constitui cientificamente, deve-se fornecer meios para que este seja o construtor de sua história, vinculando-a cognitivamente à sua capacidade crítica-reflexiva. A metodologia de ensino Dicumba faz com que o aluno, enquanto pesquisador, aprenda de forma significativa aquilo que lhe é interessante, já que se parte da perspectiva de que por meio da pesquisa não arbitrária e linear ele aprende com os erros, aprende a aprender, faz e se refaz e, de forma autêntica, amplia seu acervo cognitivo na medida em que lê e busca algo desconhecido (DEMO, 2002; GALIAZZI; MORAES, 2002).

Assim, acredita-se que esta proposta de metodologia terá um papel fundamental na formação discente e, quando utilizada em meio a competências e 
habilidades, fortalecendo o elo entre ensino e pesquisa, ressignificando os saberes científicos a partir do contexto, faz com que o sujeito não apenas questione um conhecimento ou uma prática existente, mas investigue e problematize aquilo que faz parte de sua vivência, fomentando sua capacidade de elaboração e síntese de hipóteses e problemas que substituam informações questionadas.

Desta forma, neste processo de construção e reconstrução de problemas e hipóteses sobre aquilo que pesquisou por meio do interesse e da curiosidade, o aluno forma novos conhecimentos que, ao pesquisar novamente, são questionados e problematizados, necessitando a criação de novos saberes argumentativos para explicar novamente o pesquisado; logo, cria-se um mecanismo circular de pesquisa onde a argumentação é o ponto chave deste processo. Afinal, é necessário criticar, questionar e argumentar para que algo possa ser aperfeiçoado; "é isto que possibilita pôr em movimento a pesquisa em sala de aula. O questionar se aplica a tudo que constitui o ser, quer sejam conhecimentos, atitudes, valores, comportamentos e modos de agir (ROQUE et al., 2003, p. 2). Analise a síntese na figura 1 abaixo.

Figura 1. Representação da ação do Aprender pela Pesquisa

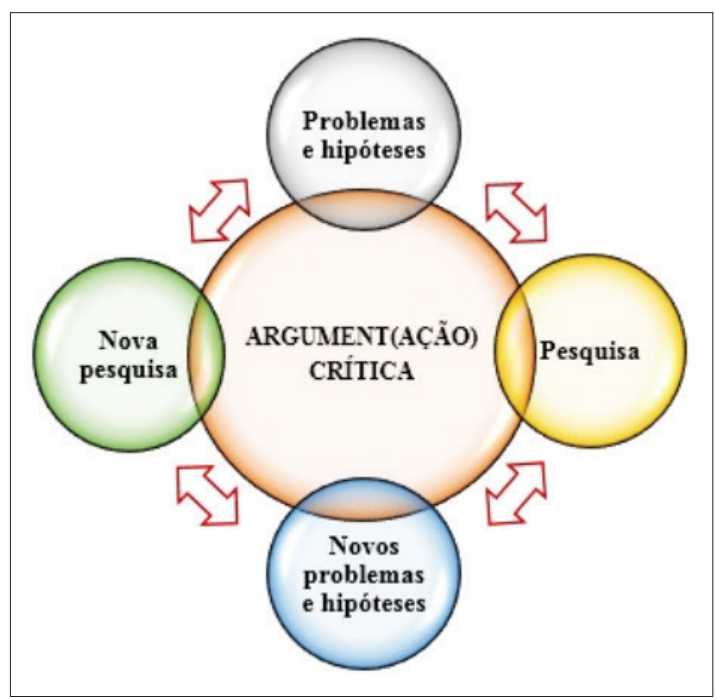

Ao observar a imagem acima, percebe-se que a argumentação perpassa as ações de problematizar e pesquisar, sendo que estas se fecundam a partir da argumentação crítica que o aluno desenvolve no ato de problematizar e elencar hipóteses referentes aquilo que deseja pesquisar, despertando seu caráter ativo no desenvolvimento de ações significativas em relação à sua formação. Após elencar um problema do seu contexto, algo que está diretamente relacionado aquilo que ele deseja estudar de maneira mais intensa, o aluno busca na pesquisa os saberes científicos que podem, de certa forma, proporcionar significados àquilo que está buscando responder/resolver. Contudo, como em um processo dialético, a pesquisa desencadeia-se em novos problemas e hipóteses, fazendo com que o aluno continue a pesquisa para responder os novos problemas que surgem. 
Nesta perspectiva, é sagaz pensar que o primeiro giro no ciclo faz com que o aluno se desenvolva mais criticamente, uma vez que a argumentação que se constrói e reconstrói a partir de novas pesquisas acaba ficando embriagada a novos saberes. É um movimento capaz de mostrar ao aluno que qualquer argumento é insuficiente para demonstrar sabedoria sobre algo, necessitando, sempre, modificálo e aperfeiçoá-lo de forma significativa a partir da pesquisa crítica-problematizada. "Tal processo propicia aos participantes desenvolverem suas potencialidades, exercitarem o uso da linguagem argumentativa, constituindo-se dessa forma, de maneira mais competente, como sujeitos" (GALIAZZI; MORAES, 2002, p. 245).

Neste sentido, é sagaz reforçar que autenticidade não é descobrir uma identidade oculta e pronta, mas alcançar um modo de se encontrar e se relacionar, o que, para Amatuzzi (1989), ocorre quando a pessoa se transforma e se relaciona a partir de sentidos, intuitos e expressões por ela admitidos, criados e constituídos conscientemente. Ou seja, o aluno perpassa por um caminho de integração - o vivido e a consciência - encurtando-se o espaço entre o sentir (experiência), o pensar (consciência, percepção da experiência) e o fazer (ação) (ROGERS, 2017), aflorando condições, a partir da autenticidade, para definir, conhecer/avaliar e, posteriormente, aperfeiçoar/mudar.

Sabe-se que estes desafios instigam a inquietação do aluno e do professor, principalmente relacionando-se a necessidade de o professor buscar/desenvolver novas práticas didático-pedagógicas que auxiliam e orientam o aluno na edificação de sua personalidade; trata-se, como afirma Rogers (1951), de uma "relação na qual pelo menos uma das partes procura promover na outra o crescimento, o desenvolvimento, a maturidade, um melhor funcionamento e uma maior capacidade de enfrentar a vida". Afinal, segundo Freire (2007), a ação de oprimir não se finaliza quando há uma inversão dos papéis de poder, sendo o oprimido de hoje um opressor amanhã; mas quando um consegue reconhecer no outro a sua autonomia e liberdade, vivendo-se em um diálogo mútuo.

\section{A METODOLOGIA DICUMBA: DAS PROPOSTAS DE TRABALHO A FORMAC̣ÃO CIDADÃ}

A ideia da constituição de uma metodologia que despertasse no aluno o interesse pela ciência surgiu, inicialmente, mediante a discussão nas Rodas de Conversa sobre o imperativo de o aluno da rede pública de ensino apresentar habilidades e competências significativas à produção do conhecimento aplicável em seu contexto, mas que, muitas vezes, são negadas ou apagadas pelo professor, já que este considera o que é curricularmente necessário o aluno aprender.

Neste desenho, espera-se que a metodologia em questão, resultante de observações, análises e discussões sobre as metodologias docentes (caminhos para desenvolver atividades nos processos de ensino e aprendizagem) e as práticas pedagógicas (formas de aplicação de atividades) realizadas na educação básica na contemporaneidade, cumpra com as seguintes características:

1. seja uma proposta construtivista-cooperativa, enfatizando o contexto de ensinagem na perspectiva de aprendizagem centrada no aluno e na 
afetividade entre os alunos e professores, garantindo uma aprendizagem bilateral a partir da problematização e da intervenção pedagógica;

2. seja uma proposta colaborativa via participação ativa do aluno no processo de aprendizagem centrada, enfatizando a mediação das informações pelo professor via construção coletiva e individual do conhecimento, emergente a partir da troca e da reflexão entre pares;

3. seja uma proposta que proporcione uma aprendizagem centrada no aluno, facilitando sua "autoformação" no viés de uma aprendizagem pela pessoa inteira;

4. seja uma proposta onde o professor atue como facilitador no processo de construção do saber, instigando o estudante a constituir sua identidade como ser plenamente atuante, transcendendo e englobando as aprendizagens cognitiva, afetiva e psicomotora;

5. seja uma proposta que propicie condições favoráveis para que os sujeitos possam, além de desenvolver competências e habilidades frente a diferentes contextos, crescer significativamente e valorizar sua formação ética, crítica, cientista e autônoma;

6. seja uma proposta que possibilita o entrosamento entre conhecimentos de níveis diferentes, configurando-se no enriquecimento mútuo pela troca de saberes, experiências e práticas que valorizam e conectam o cerne do saber popular dentro de uma teia científica e tecnológica; e

7. seja uma proposta que integre os conhecimentos gerais e, quando for o caso, técnico-profissionais realizados de formas sólida e sistematizada nas perspectivas da interdisciplinaridade e da contextualização.

Basicamente, a metodologia Dicumba pode ser interpretada por meio do mapa conceitual exposto, em forma de figura, abaixo. Nele é possível perceber que o constituir-se pleno pela pesquisa refere-se às ações de o professor e de o aluno, por meio das emoções e da problematização, interligarem-se em um mecanismo de formação mútua e dialógica do contexto ao científico. 
Figura 2. Aportes teóricos e funcionalidades da Metodologia Dicumba

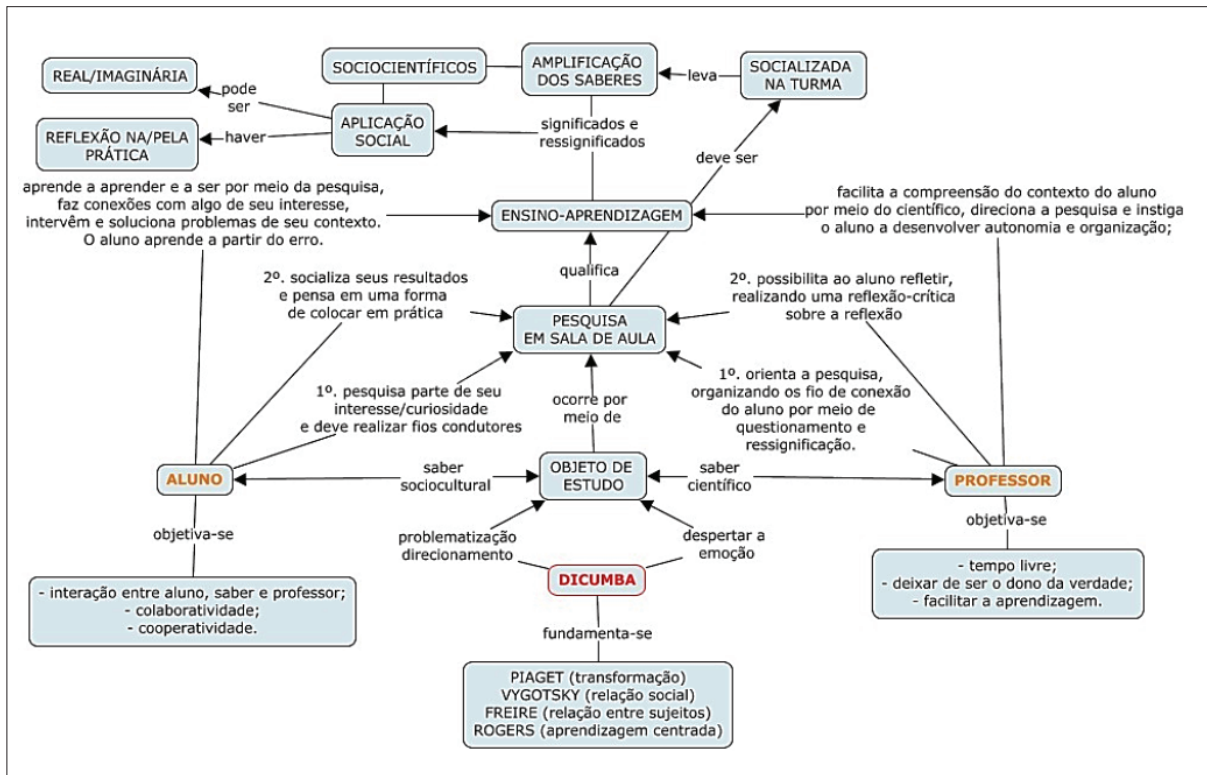

A metodologia Dicumba, fundamentalmente, ampara-se em quatro matrizes epistemológicas, as quais foram pensadas a partir de interações intrapessoal professoraluno, de tal forma que o educando, principal alvo desta metodologia, possa aprender a aprender ser a partir de suas concepções em relação ao meio e, por meio das competências e habilidades do professor, consiga ressignificar significativamente os conhecimentos científicos necessários para utilizar e impactar a sua realidade. As matrizes epistemológicas são, à luz da figura 2, Piaget, Vygotsky, Freire e Rogers.

As concepções de Piaget $(1998,1976)$ debruçam-se na ideia de transformação, aqui entendida como uma teoria do desenvolvimento mental, onde o desenvolvimento cognitivo do sujeito ocorre com assimilação e acomodação; ocorre aprendizagem quando o esquema de assimilação sofre acomodação momento em que a mente se modifica com algo estruturalmente novo; é uma forma de aprendizagem discente por descoberta, antagônico de receber passivamente do professor. Piaget, assim, afirma que o início do conhecer ocorre por meio da ação do sujeito sobre o objeto, construindo-se saberes no desenrolar desta relação; o conhecimento consiste, sequencialmente, em operação, transformação, compreensão e, na via de estímulos e sensações, adaptação ao/no objeto.

Debruça-se nas concepções de Vygotsky $(1987,1989)$ ao considerar a relação social; a construção do saber ocorre com o auxílio do outro por meio de instrumentos e signos. Para Vygotsky, o desenvolvimento humano está associado à interiorização dos instrumentos e signos que influenciam, direta e indiretamente, na zona de desenvolvimento proximal (ZDP). Trata-se de um avanço intelectual que uma criança, dentro de seu nível cognitivo, sem o auxílio de um adulto, não conseguiria desenvolver uma tarefa. Isto é importante porque ao desenvolver as ZDP, proporciona-se saltos qualitativos no desenvolvimento e na aprendizagem. 
Ainda, a metodologia ancora-se nas escrituras de Freire (2005, 2007), considerando a relação entre os sujeitos e seus saberes, pois o autor acredita que os sujeitos possuem conhecimentos, talvez oriundos de seu contexto e de sua cultura, que devem ser considerados para ressignificar e conscientizar uma realidade social. Além disso, o autor acredita na educação libertadora por meio de temas geradores em que se questiona concretamente a relação Ser humano-natureza e Ser humanoSer humano, buscando uma formação crítica. Esta formação ocorre quando "os oprimidos vão desvelando o mundo da opressão e vão comprometendo-se, na práxis, com a sua transformação; [...] esta pedagogia deixa de ser do oprimido e passa a ser dos homens em processo permanente de libertação.” (FREIRE, 2005, p. 45).

Por fim, mas não menos importante, a metodologia engaja-se, também, nos achados de Rogers (2017), potencializando a aprendizagem centrada no aluno. Para Rogers o desenvolvimento da aprendizagem deve ocorrer para que o educando seja "plenamente atuante", onde o professor passa a ser considerado um facilitador da aprendizagem. Afinal, “único homem 'educado’ é o que aprendeu a aprender; o homem que aprendeu a adaptar-se e mudar; que percebeu que nenhum conhecimento é seguro e que somente o processo de busca constante do conhecimento oferece uma base confiável e duradoura" (ROGERS, 1969 apud KONOPKA, 2015, p. 23).

Portanto, entende-se que a participação ativa e reflexiva do aluno nas atividades de ensino é reflexo de sua curiosidade e admiração, fruto do que Rogers (1959) chamou de aprendizagem significativa; o ato de aprender não depende exclusivamente de características fisiológicas, mas de aspectos emocionais e alistais nos quais o aprendiz se encontra envolvido (ROGERS, 1951).

\section{UTILIZANDO A METODOLOGIA DICUMBA NA EDUCAC̣ÃO BÁSICA: PASSOS INICIAIS}

Para intensificar e validar as escrituras neste artigo, relata-se sucintamente uma atividade desenvolvida na Educação Básica a partir da metodologia Dicumba. O desenvolvimento da atividade ocorreu com a participação ativa de 19 alunos de uma turma de $2^{\circ}$ ano do Ensino Médio de uma escola estadual no município de São Leopoldo, cidade adjacente à Porto Alegre, capital do Estado do Rio Grande do Sul.

Para tal ação, o professor titular da disciplina de química desenvolveu a metodologia Dicumba mediante 7 passos: i - explicação sobre o funcionamento da metodologia Dicumba; ii - problematização à realidade do aluno e emersão do tema de pesquisa; iii - pesquisa centrada no tema de interesse do aluno; iv - socialização da pesquisa e direcionamento ao conteúdo científico de química; v - pesquisa centrada no conteúdo científico de química relacionado ao tema de interesse do aluno; vi socialização da pesquisa científica; vii - retomada do conteúdo a partir das pesquisas.

$\mathrm{Na}$ tabela 1 abaixo, apresentam-se o tema que cada aluno escolheu para pesquisar, a justificativa em palavras-chave, dando-se ênfase ao cerne da mesma, e a conexão com o conteúdo de química relacionado pelo professor. $\mathrm{Na}$ sequência, na figura 3, apresenta-se um exemplo dos trabalhos entregues pelos alunos. 
Tabela 1. Relação dos temas escolhidos pelos alunos, suas justificativas de escolha e a relação científica com o conteúdo químico para à pesquisa

\begin{tabular}{|c|c|c|c|}
\hline Aluno & Tema & Justificativa & Relação com a Química \\
\hline 1 & $\begin{array}{l}\text { Engenharia de } \\
\text { alimentos }\end{array}$ & $\begin{array}{l}\text { - futura profissão; } \\
\text { - curiosidade. }\end{array}$ & $\begin{array}{l}\text { Explicar quimicamente os processos de } \\
\text { produção do logurte, dando ênfase a energia. }\end{array}$ \\
\hline 2 & Redes sociais & $\begin{array}{l}\text { - vício; } \\
\text { - desejo em saber. }\end{array}$ & $\begin{array}{l}\text { Influência no comportamento das pessoas } \\
\text { e a relação com os hormônios (estrutura e } \\
\text { propriedade químical no corpo. }\end{array}$ \\
\hline 3 & Cinema & $\begin{array}{l}\text { - gosto; } \\
\text { - desejo em saber. }\end{array}$ & $\begin{array}{l}\text { Diferença na dilatação da pupila com o uso do } \\
\text { colírio (composição química) e no cinema. }\end{array}$ \\
\hline 4 & TV & $\begin{array}{l}\text { - relação diária; } \\
\text { - influência. }\end{array}$ & $\begin{array}{l}\text { Formação da imagem na tela e descarte } \\
\text { correto do material. }\end{array}$ \\
\hline 5 & Mar & $\begin{array}{l}\text { - gosto; } \\
\text { - curiosidade. }\end{array}$ & $\begin{array}{l}\text { Efeitos da água na pele com e sem a ausência } \\
\text { do sol. }\end{array}$ \\
\hline 6 & Aurora boreal & $\begin{array}{l}\text { - interesse pessoal; } \\
\text { - Atraente e bela. }\end{array}$ & $\begin{array}{l}\text { Explicar a formação das cores e os ventos } \\
\text { solares. }\end{array}$ \\
\hline 7 & $\begin{array}{l}\text { Alimentação } \\
\text { saudável }\end{array}$ & $\begin{array}{l}\text { - cuidados pessoais; } \\
\text { - desejo de entender. }\end{array}$ & $\begin{array}{l}\text { Comparar a digestão entre alimento saudável } \\
\text { e não saudável. }\end{array}$ \\
\hline 8 & $\begin{array}{l}\text { Engenharia } \\
\text { química }\end{array}$ & $\begin{array}{l}\text { - futura profissão; } \\
\text { - uso de } \\
\text { medicamentos. }\end{array}$ & $\begin{array}{l}\text { Produção química do ácido acetilsalicílico, } \\
\text { dando-se ênfase a reação química. }\end{array}$ \\
\hline 9 & DST & $\begin{array}{l}\text { - curiosidade; } \\
\text { - vivência familiar. }\end{array}$ & $\begin{array}{l}\text { Explicar quimicamente como as DSTs afetam o } \\
\text { sistema imunológico. }\end{array}$ \\
\hline 10 & Música & $\begin{array}{l}\text { - influência diária; } \\
\text { - vivência. }\end{array}$ & $\begin{array}{l}\text { Liberação de hormônios ao ouvir uma música } \\
\text { triste. }\end{array}$ \\
\hline 11 & Universo & $\begin{array}{l}\text { - amor pela ciência; } \\
\text { - curiosidade. }\end{array}$ & Estudo da entropia. \\
\hline 12 & Série & $\begin{array}{l}\text { - interesse e gosto; } \\
\text { - vivencia diária. }\end{array}$ & $\begin{array}{l}\text { A importância de aprender química a partir } \\
\text { de séries que retratam este componente } \\
\text { curricular. }\end{array}$ \\
\hline 13 & Criança & $\begin{array}{l}\text { - trabalho diário; } \\
\text { - mundo de fantasia. }\end{array}$ & Composição química do colostro. \\
\hline 14 & Câncer & $\begin{array}{l}\text { - família; } \\
\text { - curiosidade. }\end{array}$ & $\begin{array}{l}\text { Funcionamento da quimioterapia e seus efeitos } \\
\text { no corpo. }\end{array}$ \\
\hline 15 & $\begin{array}{l}\text { Esportes } \\
\text { eletrônicos }\end{array}$ & $\begin{array}{l}\text { - vivência; } \\
\text { - uso diário. }\end{array}$ & $\begin{array}{l}\text { Liberação e estrutura química do hormônio } \\
\text { liberado sobre a pressão do jogo. }\end{array}$ \\
\hline 16 & Anime & $\begin{array}{l}\text { - interesse e gosto; } \\
\text { - vivência diária. }\end{array}$ & $\begin{array}{l}\text { Pesquisar sobre animes que retratam a } \\
\text { química e explicar a relação entre magia e } \\
\text { alquimia. }\end{array}$ \\
\hline 17 & Galáxia & $\begin{array}{l}\text { - interesse; } \\
\text { - gosto e curiosidade. }\end{array}$ & $\begin{array}{l}\text { Composição de marte. Explicar a ausência de } \\
\text { água em planetas próximos ao sol. }\end{array}$ \\
\hline 18 & Cachorro & $\begin{array}{l}\text { - vivência; } \\
\text { - futura profissão. }\end{array}$ & $\begin{array}{l}\text { Explicar a química da ração, apresentando as } \\
\text { propriedades das substâncias. }\end{array}$ \\
\hline 19 & Computador & - interesse. & $\begin{array}{l}\text { Composição química da máquina e descarte } \\
\text { correto do material após seu uso. }\end{array}$ \\
\hline
\end{tabular}


Figura 3. Dois exemplos de trabalhos desenvolvidos pelos alunos à luz da metodologia Dicumba
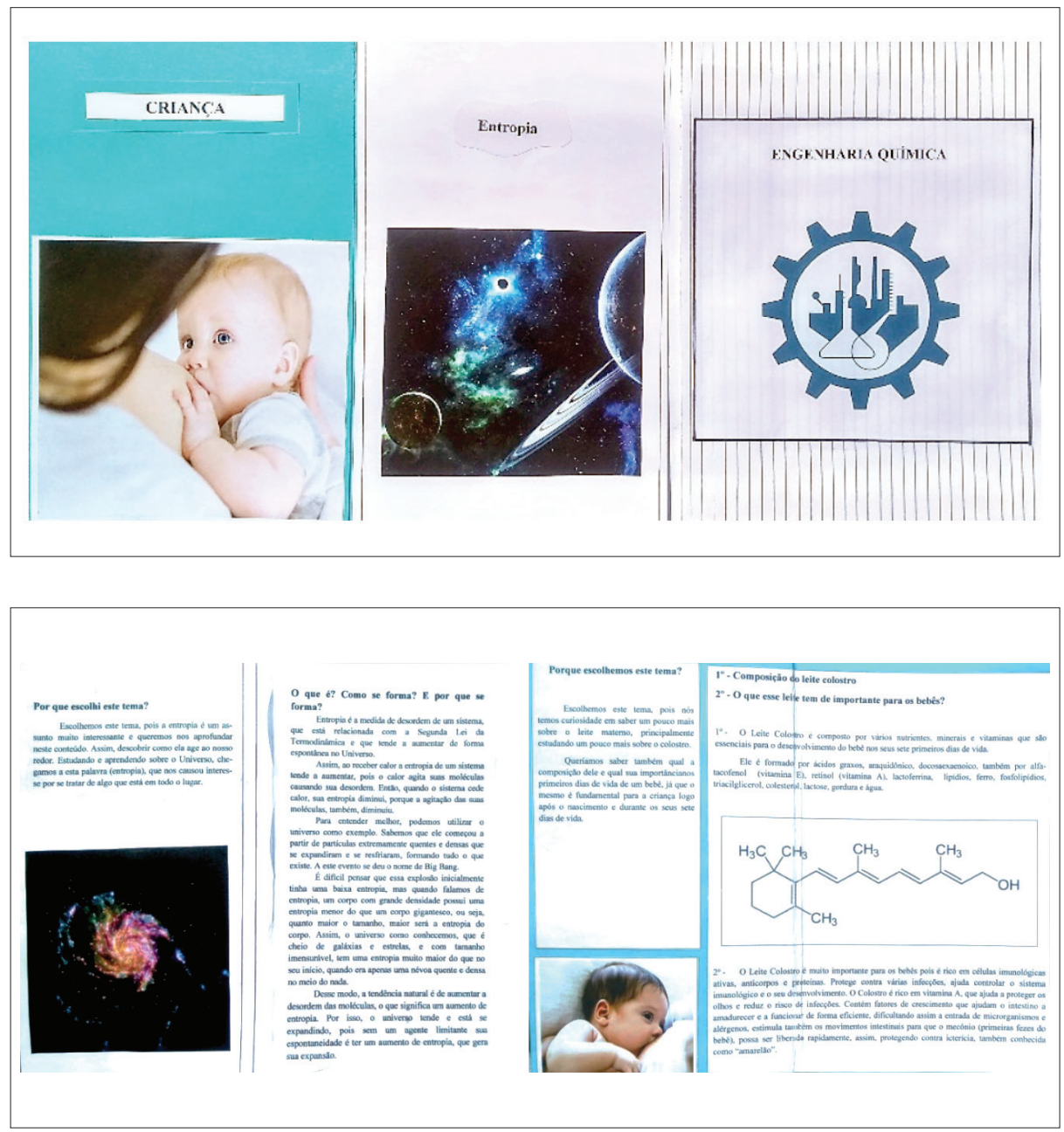

Ao término da atividade, o professor solicitou aos estudantes que, sem identificação, respondessem um questionário específico contendo sete assertivas. O questionário apresentava assertivas direcionadas à atividade e à construção do conhecimento pelo/no aluno durante todo o processo. O aluno precisava pontuar seu grau de concordância, o qual variava de -1 (discordo) a +1 (concordo), interligados por 0 (não sei opinar), em cada assertiva. A tabela 2 apresenta a totalidade da pontuação dos alunos em cada assertiva. 
Tabela 2. Assertivas e pontuações de grau de concordância pelos alunos em relação à atividade desenvolvida.

\begin{tabular}{lc}
\hline \multicolumn{1}{c}{ Assertivas } & $\mathbf{1}$ \\
\hline $\begin{array}{l}\text { A atividade me permitiu pesquisar, conhecer conceitos científicos e } \\
\text { autonomia sobre meu tema. }\end{array}$ & 18 \\
\hline $\begin{array}{l}\text { A atividade exige uma organização de pensamentos e conteúdos } \\
\text { sistematizados. }\end{array}$ & 18 \\
\hline $\begin{array}{l}\text { O trabalho é uma forma de relacionar os saberes do professor com os } \\
\text { meus, ocorrendo de forma bilateral. }\end{array}$ & 19 \\
\hline $\begin{array}{l}\text { O trabalho me proporcionou argumentação crítica e interesse pela ciência } \\
\text { química. }\end{array}$ & $\mathbf{1 7}$ \\
\hline $\begin{array}{l}\text { trabalho favoreceu minha interpretação e meu aprendizado. } \\
\text { O trabalho é uma forma de retomar o conhecimento científico a partir do } \\
\text { meu interesse. }\end{array}$ & 18 \\
\hline $\begin{array}{l}\text { Este tipo de trabalho me motiva a estudar. Partir do que eu gosto para } \\
\text { estudar química é importante. }\end{array}$ & 1 \\
\hline
\end{tabular}

Ao analisar a tabela 1, percebe-se que muitos temas não apresentam, à priori, ligação direta com o conteúdo específico de química para a segunda série do Ensino Médio, mas são conteúdos que reforçam o desejo, o interesse e a curiosidade do aluno em pesquisar para aprender, pois fazem parte da vivência e do cotidiano do mesmo. Nesta perspectiva, tem-se que a metodologia Dicumba torna possível, mediante competências e habilidades docentes, um ensino pautado na pesquisa centrada no interesse do aluno, validando, como explícito na tabela 2, o relacionamento entre os saberes do professor e o interesse de aprendizagem do aluno.

Esta ação é importante porque o aluno, durante o processo de pesquisar a química relacionada ao tema de interesse, desenvolve habilidades de criticidade, argumentação e reconstrução de ideias, pois o processo exige do sujeito a mobilização de competências referentes ao ato de aprender. Ainda, em relação ao professor, a metodologia instiga a necessidade de um aperfeiçoamento contextual dos saberes, pois quando o aluno estipula um tema de pesquisa que não está diretamente relacionado ao conteúdo de química, por exemplos, crianças e cachorro, o professor precisa pesquisar profundamente o tema para, então, pensar e relacioná-lo com o conteúdo de química; esta ação faz com que o professor busque uma formação continuada a partir de um tema macro da realidade do aluno.

Ademais, ainda referente à tabela 2, pode-se perceber que mais de $90 \%$ dos alunos concordam com as assertivas relacionadas à metodologia Dicumba em relação à motivação em aprender, a retomada de conteúdos, a constituição da argumentação crítica e, principalmente, ao interesse pela ciência a partir de um estudo realizado sobre àquilo que lhe é importante. Estas ações demonstram que a metodologia Dicumba proporciona uma ação sobre os processos de ensino e aprendizagem que permeiam a educação tradicional atual, instigando-nos a pensar a aprendizagem a partir das concepções do aluno. 
Trata-se de um posicionamento crítico no sentido de o aluno aprender ciências a partir daquilo que lhe é interessante e útil, caminhando para uma aprendizagem mais satisfatória e significativa. Assim, acredita-se, engajando-se nas palavras de Roger (2001), que a aprendizagem não será uma acumulação de fatos, mas uma forma de provocar modificações seja no comportamento, na orientação futura ou nas suas atitudes e personalidade do indivíduo. Já que, por meio da metodologia, o aluno será autor de sua aprendizagem de forma penetrante, não se limitando a um aumento de conhecimentos, mas adentra profundamente todas as parcelas da sua existência.

Neste sentido, em forma de um receituário, abaixo apresentam-se os passos de aplicação da metodologia no ensino de ciências. Ressalva-se que a forma de desenvolvimento, assim como as estratégias de ensino e as didáticas/práticas que o professor utilizar no decorrer da mesma, são referentes ao grupo heterogêneo de alunos da sala de aula; portanto, aqui não se faz jus a utilização de nenhum material, já que esta ação é exclusiva ao professor e a infraestrutura da escola.

Para iniciar as atividades à luz da metodologia Dicumba, ajuíza-se a necessidade de o professor, além de utilizar algo para instigar as emoções dos alunos, tenha conhecimentos significativos em relação a neurociência. Afinal, a ação de aprender e a memória são fenômenos comportamentais pertinentes à plasticidade do sistema nervoso central. De modo estrutural, o fenômeno de aprender é um processo em que os sistemas celulares e moleculares cerebrais decompõem uma informação em um traço de memória; "é uma modificação de comportamento que envolve a mente e o cérebro. Aprender envolve o pensamento, as emoções, as vias neurais, os neurotransmissores, enfim, todo o ser humano" (DE OLIVEIRA, 2013, p. 20).

Nesta perspectiva, parte-se do pressuposto de que a memória é pontochave na aprendizagem a partir da ressignificação de saberes preexistentes, e que as emoções estão diretamente relacionadas à capacidade de aprendizagem, pois o aprendizado pode ser acentuado como uma mudança no comportamento que resulta de uma experiência, e a memória definida como o processo pelo qual aquilo que é aprendido persiste ao longo do tempo e pode ser evocado (SQUIRE; KANDEL, 2000); logo, a ideia de instigar a emoção para trabalhar com a metodologia Dicumba decorre da percepção de que quanto mais emotivo o aluno estiver, mais significativamente ele conseguirá armazenar as informações e transformá-las em conhecimentos.

Afloradas as emoções do aluno, o professor precisa problematizar o seu contexto com algo que instigue sua curiosidade, fazendo-o encontrar um objeto de estudo. O objeto de estudo é a temática que o estudante irá investigar, pesquisar e interpretar, de acordo com suas necessidades e curiosidades, entrelaçando-a em seu contexto sociocultural por meio da pesquisa em sala de aula. É neste objeto de estudo que o professor irá concentrar seus conhecimentos científicos, buscando na vivência do aluno, subsídios para desenvolver e proliferar suas ações e ressignificar aquilo que é importante para o aprendiz.

Neste desenho, o professor vai organizando os fios condutores para que o aluno, em meio às dificuldades, situações que o faz aprender a aprender, solucionar problemas, suprir obstáculos e aprender com o erro, possa desenvolver-se por completo à qualificação dos processos de ensino e aprendizagem. Além do mais, cabe ao professor, deixando de ser o detentor do saber, possibilitar ao aluno 
refletir sobre seus saberes ressignificados, realizando uma autorreflexão crítica sobre o ato de aprender.

Neste sentido, o professor passa a ser compreendido como um facilitador da aprendizagem, pois promove a conexão entre o científico e o contexto do aluno, estimulando-o a desenvolver autonomia e organização; o estudante, por meio da pesquisa em sala de aula, adquire competências e habilidades cognitivas que farão parte de sua formação a partir da investigação sobre aquilo que julga ser importante para sua concepção, pois conhece a realidade em que fará uso e aplicação.

Ao término da atividade realizada pelo aluno e orientada pelo professor, agora rica em conceitos sistematizados e hibridizados entre sua vivência e o científico, deve-se possibilitar a socialização das atividades em sala de aula para, dentro das particularidades e singularidades de cada turma, ampliar os saberes sociocientíficos de forma cooperativa e colaborativa, a fim de significá-los na aplicação social, a qual demanda uma reflexão sobre os impactos de sua ação sobre o ambiente e o seu contexto.

Ainda, é pertinente refletir que neste momento, há de se fazer, por parte do professor e no coletivo dos alunos, um resgate dos principais conceitos emergidos na pesquisa para, em meio ao diálogo e troca de saberes de forma dialógica, possibilitar a interpretação, a compreensão e a ressignificação daquilo estudado, enriquecendo a atividade realizada e adequando-a para o desenvolvimento da aprendizagem plena do aluno, pois "quem ensina aprende ao ensinar, e quem aprende ensina ao aprender" (FREIRE, 2002, p. 25).

A atividade proposta por meio da metodologia Dicumba pode ser compreendida através de um pentagrama (símbolo da união e da síntese), em que se reúnem as cinco principais ações que se entrelaçam na medida em que são desenvolvidas as ações propostas. Analise a figura 4 abaixo.

Figura 4. Pentagrama - ações desenvolvidas na metodologia Dicumba

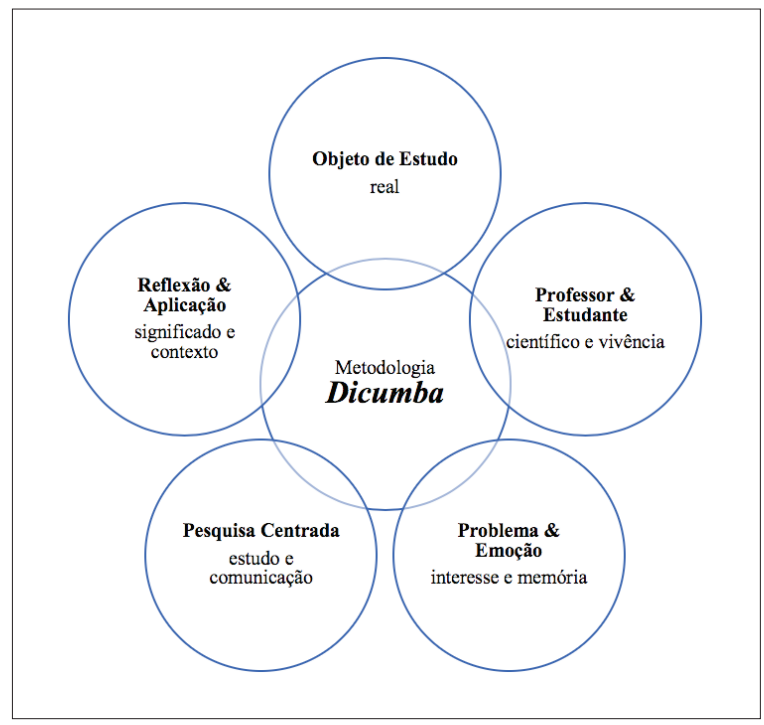


Analisando-se o pentagrama, pode-se aferir que a metodologia pressupõe a relação entre os sujeitos envolvidos no processo de ensinagem de forma assídua, participativa e cooperativa, contemplando um objeto de estudo real que deriva da curiosidade do aluno a partir de sua realidade. De outra forma, a pesquisa é centrada no aluno e orientada pelo professor, a partir da problematização, do interesse do aluno e de suas emoções à luz da memorização, em meio a estudos e comunicações que levam à reflexão sobre a aplicação do objeto estudado e ressignificado em seu contexto.

Nesta perspectiva, entende-se que por meio da pesquisa o aluno torna-se mais ativo e comprometido com o processo de aprendizagem. A ação de pesquisar aquilo que lhe é interessante e aprender a partir da contextualização dos saberes sociais com o científico, por meio da motivação, da participação, do questionamento e da dúvida, possibilita-lhe construir consciência crítica e expressar conhecimento específico na (re)construção de saberes e na produção de novos conhecimentos.

Não obstante, a imagem abaixo reflete o que se espera com o desenvolvimento da metodologia Dicumba em sala de aula em relação ao cognitivo do aluno e a relação deste com o meio, por meio de ações, a partir da pesquisa em sala de aula pela ação da metodologia Dicumba.

Figura 5. Ações cognitivas do aluno à luz da metodologia Dicumba

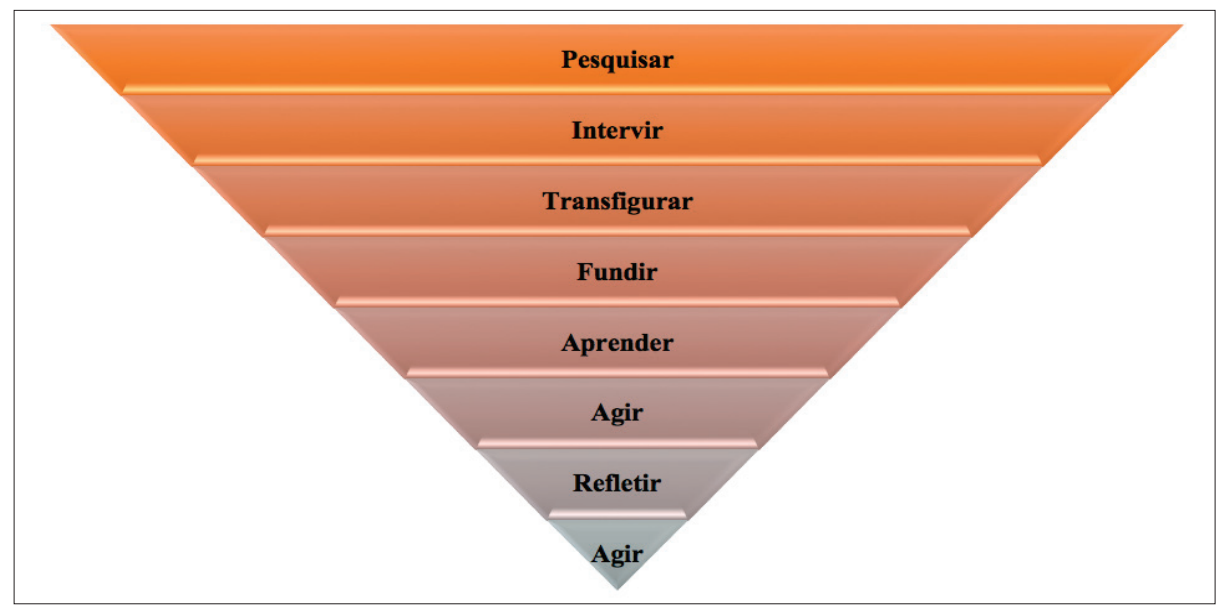

Ao analisar a pirâmide-inversa acima, a qual deriva das ações propostas na metodologia Dicumba, pode-se aclarar que ela parte do conhecimento macro do aluno, àquele específico de sua vivência, onde ele realiza uma pesquisa centrada em seu interesse, e afunila-se para saberes micro, àqueles relacionados aos conhecimentos científicos direcionados pelo professor e construído ao longo de um processo.

No decorrer do processo de (re)construção de conhecimento, ações como fundir, transfigurar e aprender ocorrem simultaneamente para, posteriormente, com os saberes regados ao conteúdo científico, o aluno agir e refletir sobre sua realidade. Basicamente, a partir da pesquisa, o aluno começa a ampliar seu acervo de informações sobre aquilo que lhe é interessante; ele rega-se de novas 
informações e ressignifica conhecimentos existentes para, então, intervir sobre o meio e começar a realizar assimilações.

Diante das colocações da ação da metodologia Dicumba, percebe-se que esta volta-se para uma abordagem de aprendizagem centrada no aluno, utilizandose o método não linear e não diretivo, ou seja, o professor não interfere diretamente no campo cognitivo e afetivo do aluno, mas facilita para que o mesmo encontre aquilo que está buscando; aquilo que lhe tem sentido e importância. Assim, a metodologia Dicumba, regando-se a visão de Rogers (1978), concentra-se em um modelo de ensinagem em que o indivíduo tem a liberdade e a responsabilidade para escolher os caminhos que subsidiarão a construção do conhecimento, o qual se concretiza de forma satisfatória quando o aluno atuar como um agente ativo e o professor como um facilitador nesse processo.

Neste sentido, pode-se perceber que o estudante é o centro da sala de aula, onde pode selecionar os conteúdos que julga serem necessários e importantes para sua formação, pois é o único que, significativamente, conhece seu contexto e sua realidade. Em outras palavras, partindo de saberes macroscópicos (saberes advindos do aluno) a metodologia Dicumba potencializa a relação intrapessoal entre o aluno e o professor - agora facilitador - em um viés cooperativo, possibilitando ao aluno a liberdade de expressão sem nenhum convencionalismo ou aversão e, ao contrário da aplicação de uma avaliação formal, como destacado por Rogers (1978), promover o processo de autocrítica e autoavaliação por parte do aluno.

Neste desenho, ajuíza-se que a metodologia que aqui se apresentou busca uma forma diferenciada e, quiçá, mais qualificada àquelas que hoje entrelaçam as ações pedagógicas nas diferentes escolas do país, pois, na metodologia Dicumba, não há regras; o estudante passa a ser atuante de sua aprendizagem e um ser ativo no processo de sua formação, aprendendo o científico a partir da natureza essencial de sua formação. Destarte, “o objetivo de nosso sistema educacional, desde a escola maternal até a escola de pós-graduação, deve derivar-se da natureza dinâmica de nossa sociedade caracterizada por mudança, não por tradição, por processo, não por rigidez estática", seu objetivo "deve ser o desenvolvimento de pessoas plenamente atuantes”. (MILHOLLAN; FORISHA, 1978. p.175-176).

\section{CONSIDERAÇÕES FINAIS}

Esta pesquisa buscou apresentar e refletir sobre uma proposta de metodologia de ensino que pode assegurar, desenvolvida de forma significativa, a aquisição de saberes expressivos na aprendizagem do aluno com vistas à sua formação plena. Ou seja, objetivou-se apresentar a metodologia Dicumba como uma estratégia pedagógica no contexto investigado e problematizador da sala de aula, emergente nas discussões e reflexões de um grupo de professores preocupados com o aprendizado e crédulos no potencial dos alunos, durante as Rodas de Conversa.

No desenrolar do artigo, percebeu-se que a proposta metodológica visa constituir a figura do professor como um facilitador do processo de aprendizagem, instigando o aluno, por meio da emoção e da problematização, a se compor como autônomo e responsável pela sua formação, construindo e reconstruindo, por meio da pesquisa desenvolvida em sala de aula a partir daquilo que lhe é interessante, em 
uma visão não linear e arbitrária, criticamente e com veracidade, conhecimentos através das descobertas.

Ainda, em meio ao texto, pode-se perceber que a metodologia Dicumba é uma forma didática de trabalhar o ensino de ciências por pesquisa, instigando nos professores e nos alunos a constituição de competências e habilidades para trabalhar e respeitar o outro, evidenciando que o aprendizado ocorre de forma sistêmica pela problematização e pelo diálogo, além de que o aluno aprende o científico a partir de sua realidade e daquilo que lhe é útil e interessante.

A pesquisa em sala de aula é uma das maneiras de envolver os sujeitos, alunos e professores, num processo de questionamento do discurso, das verdades implícitas e explícitas nas formações discursivas, propiciando a partir disso a construção de argumentos que levem a novas verdades. A pesquisa em sala de aula pode representar um dos modos de influir no fluxo do rio. Envolver-se nesse processo é acreditar que a realidade não é pronta, mas que se constitui a partir de uma construção humana (GALIAZZI; MORAES; RAMOS, 2002, p. 10).

Assim, entende-se que a metodologia proposta é uma forma de aproximar os saberes do contexto do aluno com os saberes científicos do professor a partir do interesse do aluno; logo, a metodologia tem o intuito de aproximar o professor do aluno, o aluno do aluno e, dentre outros fatores, fazer com que o aluno busque as informações e, em meio as ressignificações e contextualizações do professor, consiga transformá-las em conhecimento para produzir novos saberes em seu processo de formação.

Destarte, acredita-se que a metodologia Dicumba possa somar de forma significativa às metodologias de ensino que vinculam a pesquisa como prática de formação discente e docente; contudo, ressalva-se que esta metodologia destacase por fazer com que o professor desenvolva seus saberes a partir da vivência do aluno, não norteando e direcionando a pesquisa do aluno para seus conhecimentos predeterminados no currículo, mas que, a partir do interesse e do fascínio de pesquisa do aluno, o professor consiga direcionar seus saberes de forma útil e conveniente.

Por fim, é cogente mencionar que o grande desafio do professor e da escola é inserir a pesquisa como mecanismo de formação plena do aluno, fazendo-o pegar as "rédeas" do conhecimento e, a partir das dificuldades e dos erros", aprender a aprender com sabedoria, autonomia e veracidade. Em suma, é preciso, além de censurar, repensar o papel do professor, recriando-o na direção do facilitador da construção e aquisição dos conhecimentos. Portanto, é imprescindível, para fazer com que o aluno seja autor de sua formação e o professor coautor, trabalhar com a metodologia Dicumba no ensino de ciências, pois ela pode ser compreendida como um processo que produz conhecimentos significativos e utilitários para o aluno a partir da mudança e da qualidade na prática pedagógica.

\section{REFERÊNCIAS}

AMATUZZI, M. O resgate da fala autêntica. Campinas, Papirus, 1989.

ASSMANN, H. Reencantar a educação: rumo à sociedade aprendente. Petrópolis: Vozes, 1998 
BAKHTIN, M. Marxismo e Filosofia da Linguagem. 9ª ed. São Paulo: Hucitec, 1999.

BEDIN, E.; DEL PINO, J. C. Concepções de professores sobre situação de estudo: rodas de conversa como práticas formadoras. Interfaces da Educ., Paranaíba, v. 8, n. 22, p.154-185, 2017a.

BEDIN, E.; DEL PINO, J. C. Propostas metodológicas docentes à luz das situações de estudo. Revista educ. em rede: formação e prática docente, v. 6, n. 7, p. 83-99, jun. 2017b. Disponível em: <http:/ / ojs.cesuca.edu.br/index.php/educacaoemrede/article/view/1297>. Acesso em: 04 jul. 2017.

BERTOLETTI, A. C. et al. Educar pela Pesquisa-uma abordagem para o desenvolvimento e utilização de Softwares Educacionais. RENOTE, v. 1, n. 2, 2003.

BRASIL. Conselho Nacional de Educação. Diretrizes Nacionais para a Educação em Direitos Humanos. Resolução CNE/CP $\mathbf{n}^{\circ}$ 1, de 30 de maio de 2012. Brasília, Diário Oficial [da] República Federativa do Brasil, 31 de maio de 2012, Seção 1, p. 48.

BRASIL. Conselho Nacional de Educação/Conselho Pleno. Diretrizes Curriculares para a Formação de Professores da Educação Básica, em nível superior, curso de licenciatura, de graduação Plena. Brasília, Resolução CNE/CP 1, de 18 de fevereiro de 2002.

DE OLIVEIRA, G. G. Neurociências e os processos educativos: um saber necessário na formação de professores. Educação Unisinos, v. 18, n. 1, p.13-24, 2013. Disponível em: <http://revistas. unisinos.br/index.php/educacao/article/view/1881>. Acesso em 15 set. 2018.

DEMO, P. Educar pela pesquisa. 5ª ed. Campinas, SP. Autores Associados, 2002. 120 p.

FREIRE, P. Em busca de sentido: um psicólogo no campo de concentração. 16a ed. Petrópolis/ São Leopoldo, Vozes/Sinodal, 2002.

FREIRE, P. Um sentido para a vida: psicoterapia e humanismo. Tradução Lapenta, V. H. S. $13^{a}$ ed. Aparecida, SP, Editora ideias \& letras, 2005.

FREIRE, P. Pedagogia do oprimido. 46ª ed. Rio de Janeiro, Paz e Terra, 2007.

GALIAZZI, M.; MORAES, R.; RAMOS, M. Pesquisas em sala de aula: fundamentos e pressupostos. In: LIMA, V. M. R; MORAES, R. (org.). Pesquisa em sala de aula: tendências para a educação em novos tempos. Porto Alegre: EDIPUCRS, 2002. 316 p.

GALIAZZI, M. do C.; MORAES, R. Educação pela pesquisa como modo, tempo e espaço de qualificação da formação de professores de ciências. Ciência \& Educação (Bauru), v. 8, n. 2, p. 237-252, 2002.

MILHOLLAN, F.; FORISHA, B. Skiner \& Rogers: maneiras contrastantes de encarar a educação. São Paulo, Summus Editorial, $8^{\mathrm{a}}$ Ed, 1978.

MORAES, R.; GALIAZZI, M. C.; RAMOS, M. G. Pesquisa em sala de aula: fundamentos e pressupostos. In: MORAES, R.; LIMA, V. M. R. (ed.). Pesquisa em sala de aula: tendências para a educação em novos tempos. Porto Alegre, Brasil: Edipucrs, 2012.

NASCIMENTO, M. A. G. do.; SILVA, C. N. M. da. Rodas de conversa e oficinas temáticas: experiências metodológicas de ensino-aprendizagem em geografia. In: X Encontro Nacional de Práticas de Ensino em Geografia - ENPEG, Porto Alegre, 2009. Disponível em: http://www. agb.org.br/XENPEG/artigos/Poster/P\%20(36).pdf. Acessado em: 20 de jun. 2017.

PIAGET, J. A equilibração das estruturas cognitivas. Rio de Janeiro: Zahar, 1976.

PIAGET, J. A evolução social e a pedagogia nova. In: PIAGET, J. Sobre a pedagogia: textos inéditos. São Paulo: Casa do Psicólogo, 1998. p. 97-111. 
PIAGET, J. Tornar-se pessoa. São Paulo: Martins Fontes, 1991.

PIAGET, J. Liberdade para aprender. Tradução Machado, E. G. M. e Andrade, M. P. $4^{a}$ ed. Belo Horizonte, Interlivros de Minas Gerais, 1978.

PIAGET, J. Tornar-se pessoa. Tradução Ferreira, M. J. C. e Lamparelli, A. $3^{a}$ ed. São Paulo, Martins Fontes, 2001.

PIAGET, J. Um jeito de ser. São Paulo, E.P.U, 2003.

PICCOLI, S. M.; MORAES, R. Ensinar e aprender pela pesquisa: um desafio para uma formação continuada de professores. Revista de Ciências Humanas, v. 7, n. 8, p. 91-106, 2006.

ROGERS, C. R. Tornar-se pessoa. WWF Martins Fontes, 2017.

ROGERS, C. R. Liberdade para aprender. Belo Horizonte: Interlivros, 320 p., 1978, p. 19-316, passim.

ROGERS, C. R. Freedom to learn. Columbus, Ohio: Charles Merril, 1969. In: KONOPKA, C. L. A aprendizagem na concepção humanista de Carl Rogers e sua contribuição para o desenvolvimento das atitudes dos estudantes de graduação em medicina da UFSM. (Tese de Doutorado) Programa de Pós-Graduação em Educação em Ciências: Química da Vida e Saúde, UFSM. 2015. Disponível em: <https://repositorio.ufsm.br/bitstream/handle/1/3548/KONOPKA $\% 2$ C $\% 20$ CLOVIS $\% 20$ LUIS.pdf? sequence $=1 \&$ is Allowed $=\mathrm{y}>$. Acesso em: 10 set. 2018 .

KONOPKA, C. L. Significant learning in therapy and in education. Alexandria, VA: Educational Leadership, n. 16, p. 232-242, 1959.

KONOPKA, C. L. Client-centered Therapy: Its Current Practice, Implications and Theory. Londres: Constable, 1951.

SCHMIDT, R. Cell-adhesion molecules in memory formation. Behav Brain Res. 1995.

SQUIRE, L.; KANDEL, E. Memory: from mind to molecules. New York: W.H. Freeman and Company; 2000.

VLACH, V.; LIMA, M. Geografia escolar: relações e representações da prática social. In: Revista Caminhos da Geografia, v. 3, n. 5, 2002. Disponível em: < http://www.seer.ufu.br/index.php/ caminhosdegeografia/article/view/15289>. Acesso em: 28 dez. 2017.

VYGOTSKY, L. Pensamento e linguagem. São Paulo: Martins Fontes, 1987.

VYGOTSKY, L. A formação social da mente: o desenvolvimento dos processos psicológicos superiores. $3^{\mathrm{a} e d . ~ S a ̃ o ~ P a u l o: ~ M a r t i n s ~ F o n t e s, ~} 1989$.

VYGOTSKY, L. A formação social da mente: o desenvolvimento dos processos psicológicos superiores. $4^{\mathrm{a}}$ ed. São Paulo: Martins Fontes, 1991.

WARSCHAUER, C. A Roda e o Registro. - Uma parceria entre professor, alunos e conhecimento. Rio de Janeiro: Paz e Terra, 1993.

Submetido em 07/01/2018

Aprovado em 05/10/2018

\section{Contato:}

Everton Bedin

Universidade Luterana do Brasil - ULBRA Canoas

Avenida Farroupilha, n. 8001 - Bairro São José

CEP 92.425-900 - Canoas, RS - Brasil 